\title{
Core Flow Experiment Protocol
}

\author{
Brian E. Viani
}

Sue I. Martin

December 1997

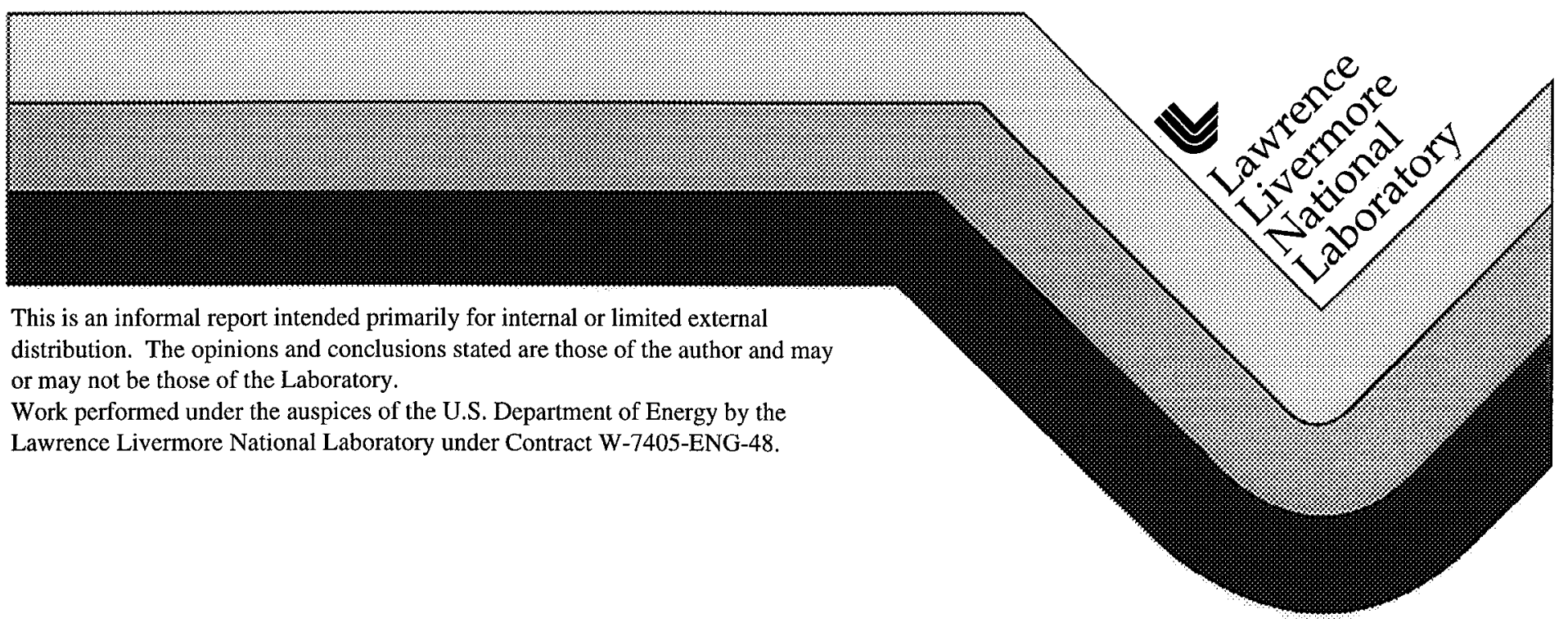




\section{DISCLAIMER}

This document was prepared as an account of work sponsored by an agency of the United States Government. Neither the United States Government nor the University of California nor any of their employees, makes any warranty, express or implied, or assumes any legal liability or responsibility for the accuracy, completeness, or usefulness of any information, apparatus, product, or process disclosed, or represents that its use would not infringe privately owned rights. Reference herein to any specific commercial product, process, or service by trade name, trademark, manufacturer, or otherwise, does not necessarily constitute or imply its endorsement, recommendation, or favoring by the United States Government or the University of California. The views and opinions of authors expressed herein do not necessarily state or reflect those of the United States Government or the University of California, and shall not be used for advertising or product endorsement purposes.

This report has been reproduced directly from the best available copy.

Available to DOE and DOE contractors from the Office of Scientific and Technical Information

P.O. Box 62, Oak Ridge, TN 37831

Prices available from (423) 576-8401

Available to the public from the National Technical Information Service

U.S. Department of Commerce 5285 Port Royal Rd.,

Springfield, VA 22161 


\title{
CORE FLOW EXPERIMENT PROTOCOL - MOL04
}

\author{
Brian E. Viani \\ Sue I. Martin \\ LLNL
}

This letter report describes the current status of the core flow through apparatus and describes the protocol and test matrix to be followed during the initial experimental stage of radionuclide transport studies in the Integrated Testing task.

\section{Present configuration of the core flow through apparatus}

The apparatus for measuring flow and transport at elevated temperatures has been modified from the original design because of the inability to maintain constant flow and inadequate temperature control (Viani and Martin, 1993). The present apparatus is shown schematically in Figure 1. It differs from the previous apparatus several key ways.

1. The pump has been changed to a $500 \mathrm{~mL}$ capacity piston type (ISCO Model 500D) that can maintain constant flow to within $+/-0.5 \%$.

2. Pore pressure is adjusted using only a down stream metering valve instead of the up and downstream valves previously used.

3. An in-line filter holder has been installed upstream of the sample input valve.

4. An automated fraction collector has been installed to which all effluent is directed.

5. The volume of effluent passing through the core sample is obtained from the volume of fluid delivered by the pump and/or the volume of fluid collected by the fraction collector, rather than by a separate gravimetric measurement.

6. A new temperature controller has been installed.

7. The LABVIEW data collection software has been modified to accept the flow rate, volume remaining, and pump pressure signals output by the ISCO pump controller.

Initial testing of the new system is underway using a cylindrical sample of Topopah Spring tuff with a 25 $\mu \mathrm{m}$ saw-cut fracture that was prepared as reported in Viani and Martin (1993). Figures 2 to 6 show results for one test run.

With the present configuration, the volume of fluid that passes the core sample is assumed to equal the volume delivered by the ISCO pump. The delivered volume calculated from the ISCO pump volume remaining signal was compared to the effluent volume measured gravimetrically and found to agree to within $0.5 \%$. Figures 2 and 3 show that the present set-up is capable of maintaining a very constant flow rate $(+/-$ $0.5 \%$ ) in contrast to the previous apparatus.

Over the approximately 120 hour test period, the permeability decreased by approximately $50 \%$ and the differential pressure increased by approximately two-fold (Figure 4). In flow tests using the previous apparatus, the decrease in permeability was related to the growth of bacteria in the system (Viani and Martin, 1993). In those tests, the flow rate also decreased until it became effectively zero. It is expected that complete blockage of the fracture by bacteria will not occur using this system in constant flow mode, because the differential pressure will automatically increase to maintain the rate. We expect to utilize flow rates be- 


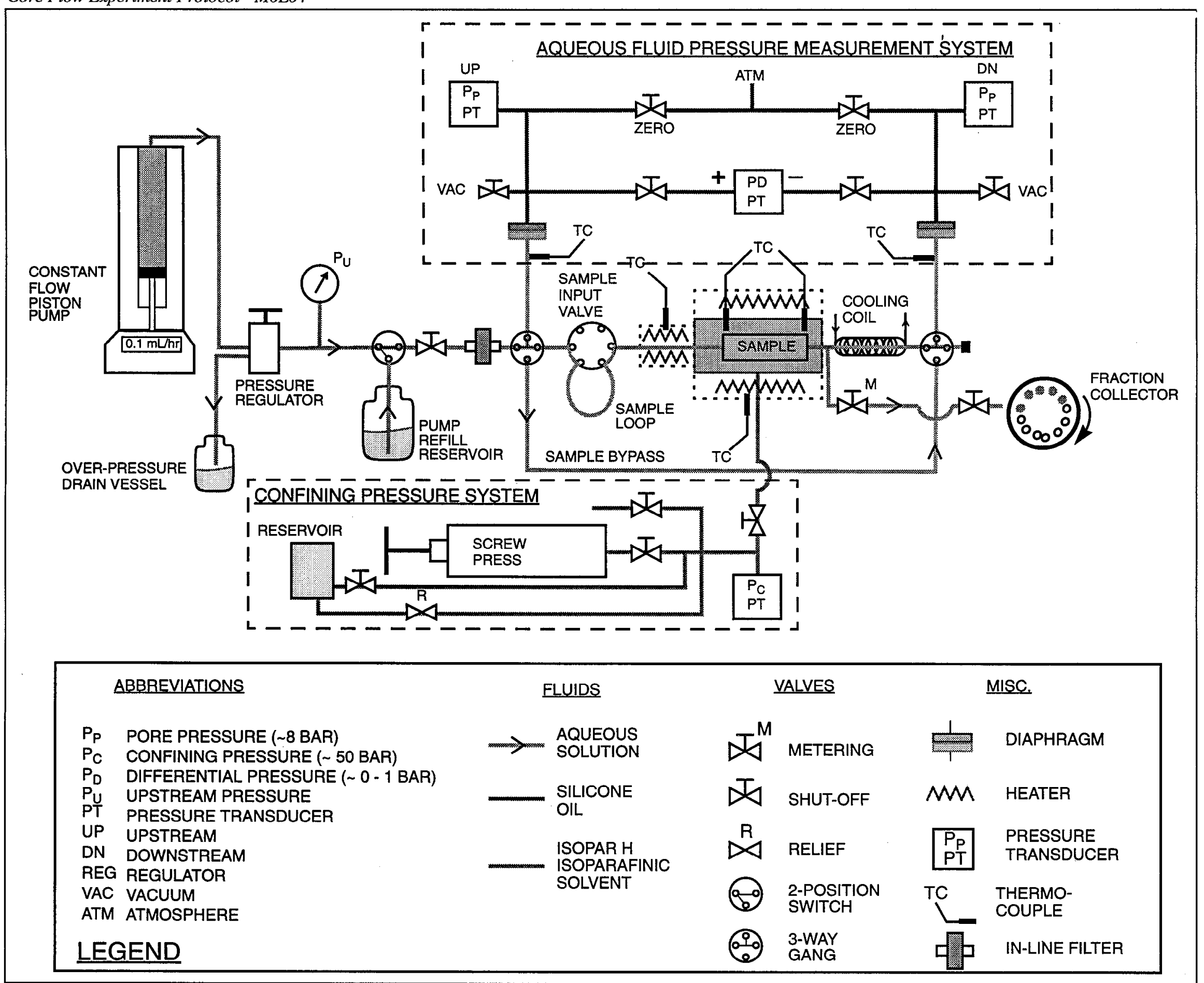

Figure 1. Schematic of core-flow apparatus. 


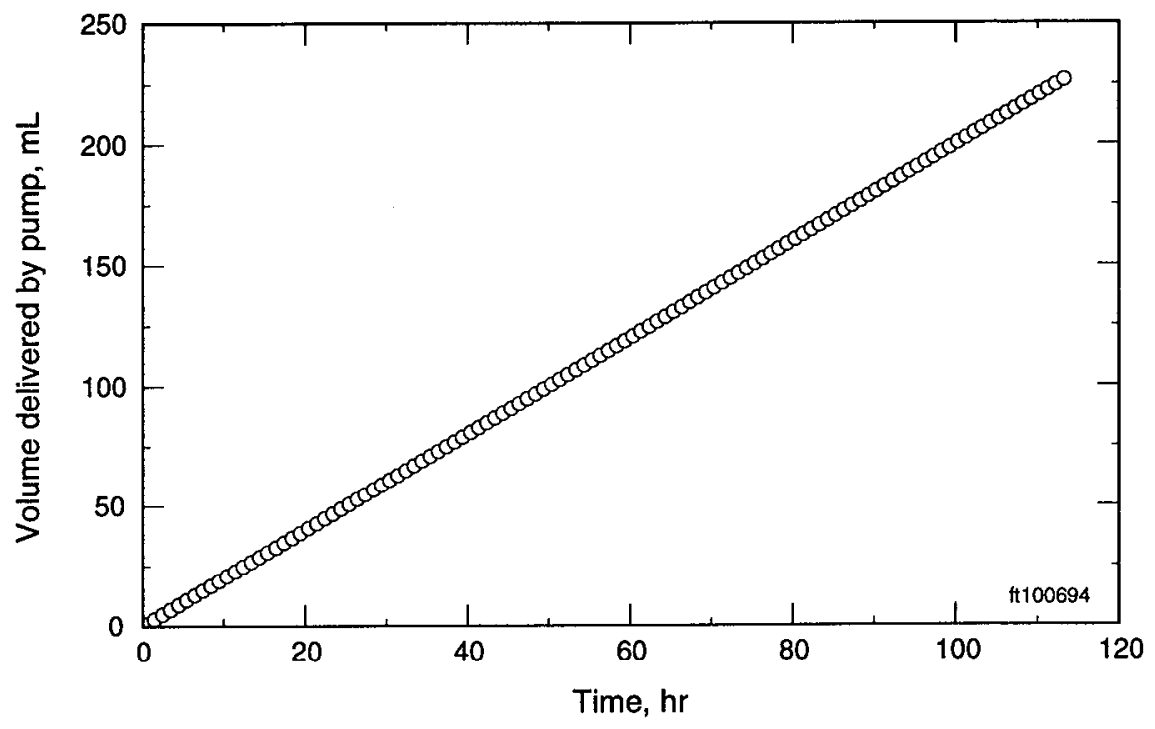

Figure 2. Cumulative volume delivered by ISCO pump vs. time.

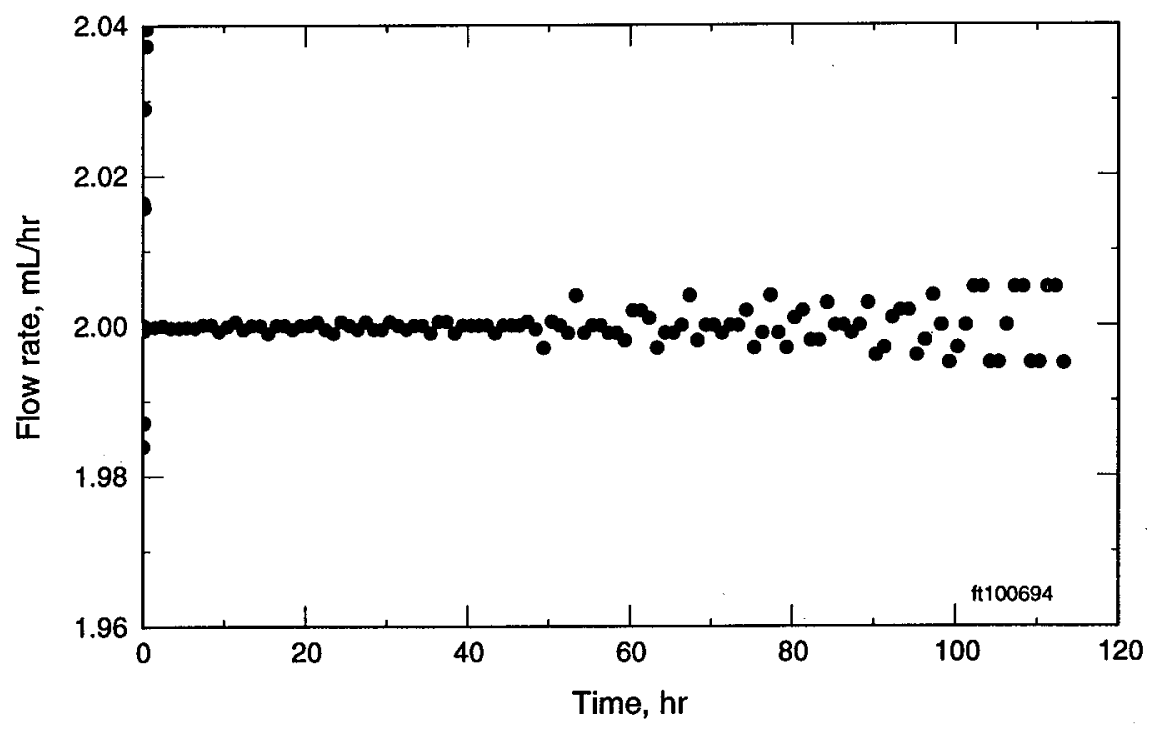

Figure 3. Flow rate as determined by numerical derivation of cumulative volume delivered.

tween 0.1 and $2 \mathrm{~mL}$ per hour. For a Topopah Spring tuff with a $25 \mu \mathrm{m}$ fracture, this flow rate range corresponds to approximately 0.01 to 0.2 total porosity volumes per hour, or 1.5 to 30 fracture porosity volumes per hour.

As noted previously (Viani and Martin, 1993), variation in ambient temperature gives rise to variation in confining pressure (Figures 5 and 6). The temperature measured at the jacket surrounding the core varies much more smoothly than either the ambient air temperature, or at the diaphragm separating the aqueous fluid stream from the silicone oil (downstream thermocouple) (Figure 1). 


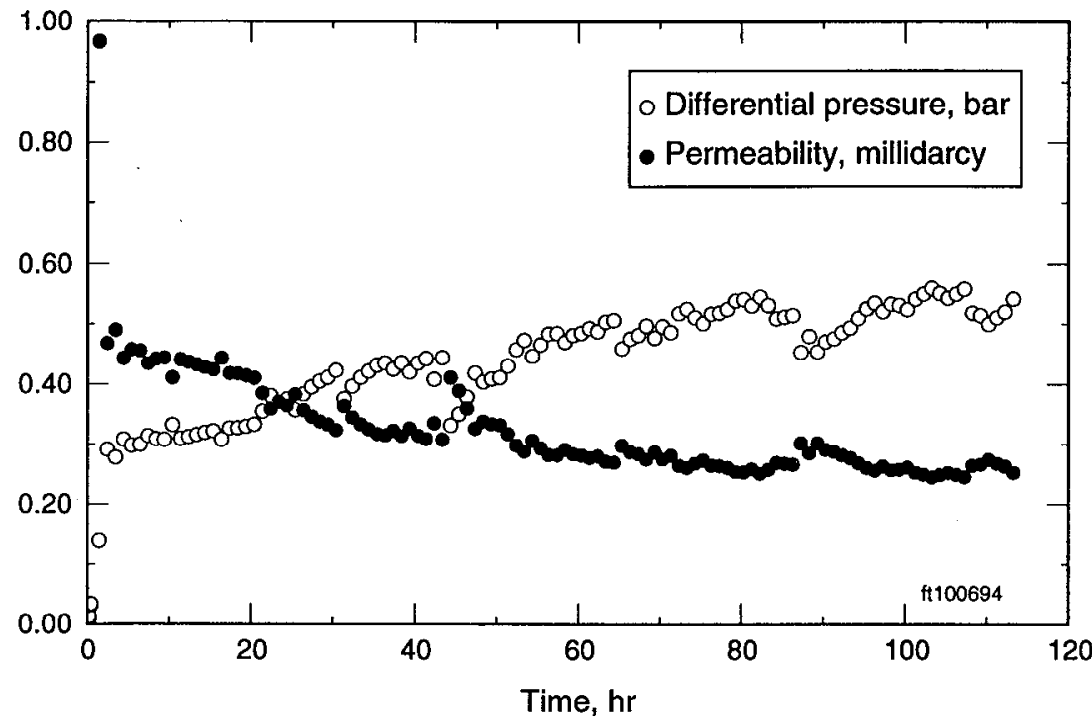

Figure 4. Variation in differential pressure and permeability during flow test.

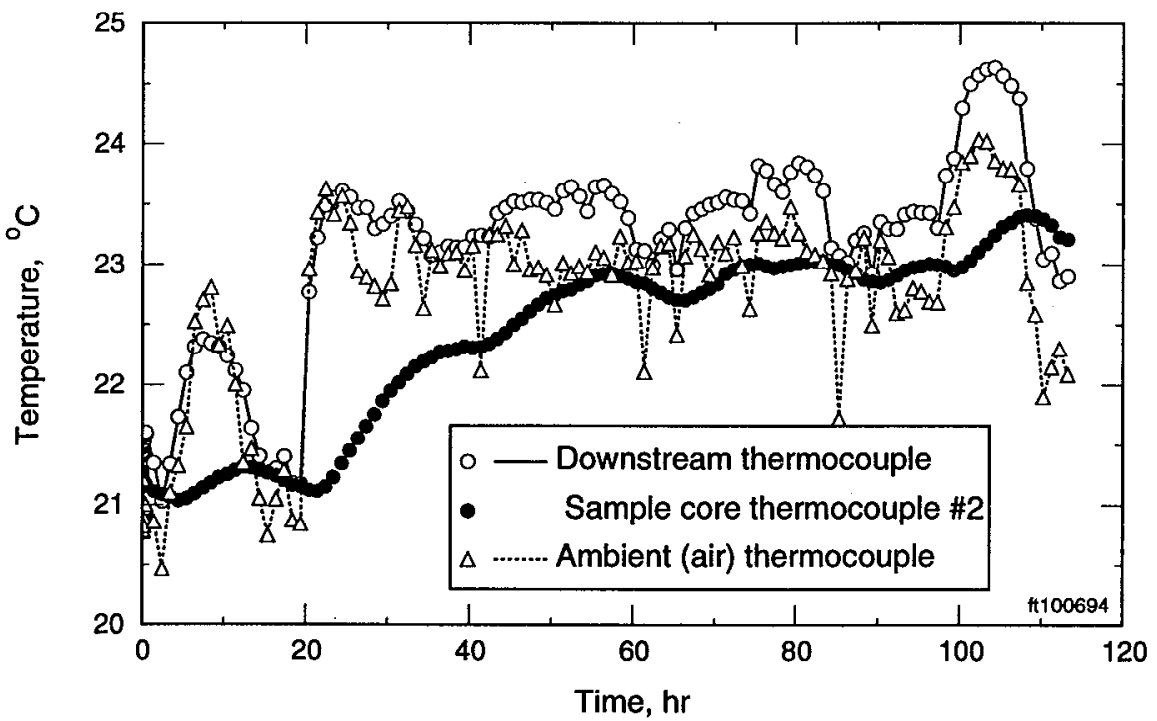

Figure 5. Variation in temperature during flow test.

\section{Protocol and test matrix for initial experimental transport test phase}

The initial testing phase will focus on the transport of two important radionuclides, $U$ and $N p$, through intact cores of devitrified Topopah Spring tuff containing a single saw-cut fracture at temperatures between ambient and ca. $100^{\circ} \mathrm{C}$. The fracture aperture for these experiments will be set at $10-25 \mu \mathrm{m}$ using gold shim. Transport will be measured at ambient and at two elevated temperatures, $\sim 60$ and ca. $100^{\circ} \mathrm{C}$. De- 


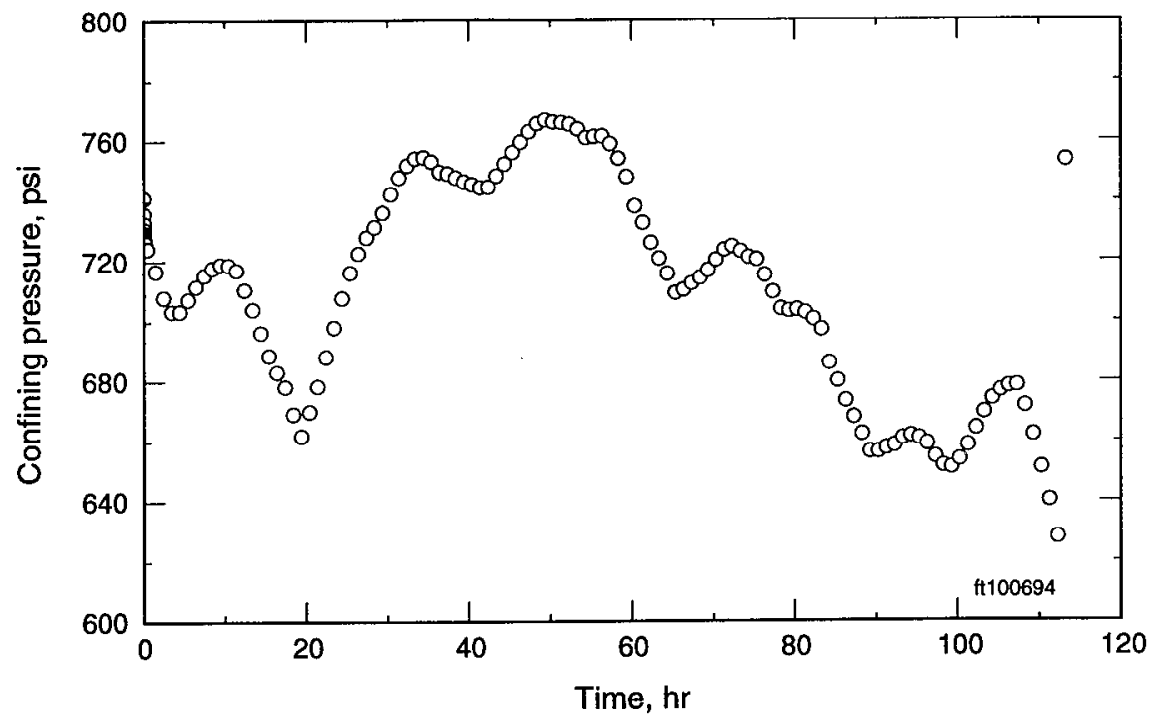

Figure 6. Variation in confining pressure during flow test.

pending on initial results, the intermediate temperature may be dropped from the test matrix in order to expedite the acquisition of transport data necessary for bounding calculations.

Three background or carrier fluids will be used for this set of experiments: 1) $\mathrm{A} \mathrm{Na}-\mathrm{HCO}_{3}-\mathrm{Cl}$ solution with an ionic strength similar to water from well $\mathrm{J}-13$ and $\mathrm{apH}$ in the range of $6-8 ; 2$ ) water from well $\mathrm{J}-13$; and, 3) water from either the Paleozoic aquifer rock (e.g. Well UE25p\#1) or water with a composition and ionic strength similar to that measured for water extracted from the unsaturated zone. All fluids will be filtered through $0.1 \mu \mathrm{m}$ filters. Carrier fluids will be delivered by the piston pump; conservative tracer ( $\left.\mathrm{Br}^{-}\right)$and radionuclide bearing solutions will be introduced through the sample input port. Only the +6 oxidation state of $\mathrm{U}$ and $\mathrm{Np}$ will be utilized for these studies.

For each type of carrier fluid a series of tests will be undertaken using two or potentially one core sample (Figure 7). In order to save time and expense, an attempt will be made to perform transport experiments for $\mathrm{U}$ and $\mathrm{Np}$ on the same core sample. Flushing the sample with carrier fluid will be used to attempt to recover as much of the added $\mathrm{U}$ as possible prior to introduction of the $\mathrm{Np}$. If this does not prove feasible, a new core will be used for each radionuclide.

Subtasks and analytical methods to be used are listed in Table 1. Because of the limited sample volumes expected, complete fluid chemical analyses will be measured on selected pooled sample fractions. Bromide, $\mathrm{U}$ and $\mathrm{Np}$ will be analyzed for all samples collected after the introduction of the respective tracers.

The length of time to accomplish each transport experiment will be variable and will depend on flow rate, adsorption/desorption coefficients and kinetics, and matrix diffusion rates. Presently, approximately three months laboratory time are estimated to perform the experiments for each carrier fluid, if a single core can be utilized for each radionuclide, and if only a single elevated temperature run is performed.

The data will be analyzed using currently available coupled flow/transport codes. Where possible, adsorption and diffusion coefficients for these radionuclides in these types of rocks will be obtained from other project participants (Los Alamos National Laboratory) or from the literature. 


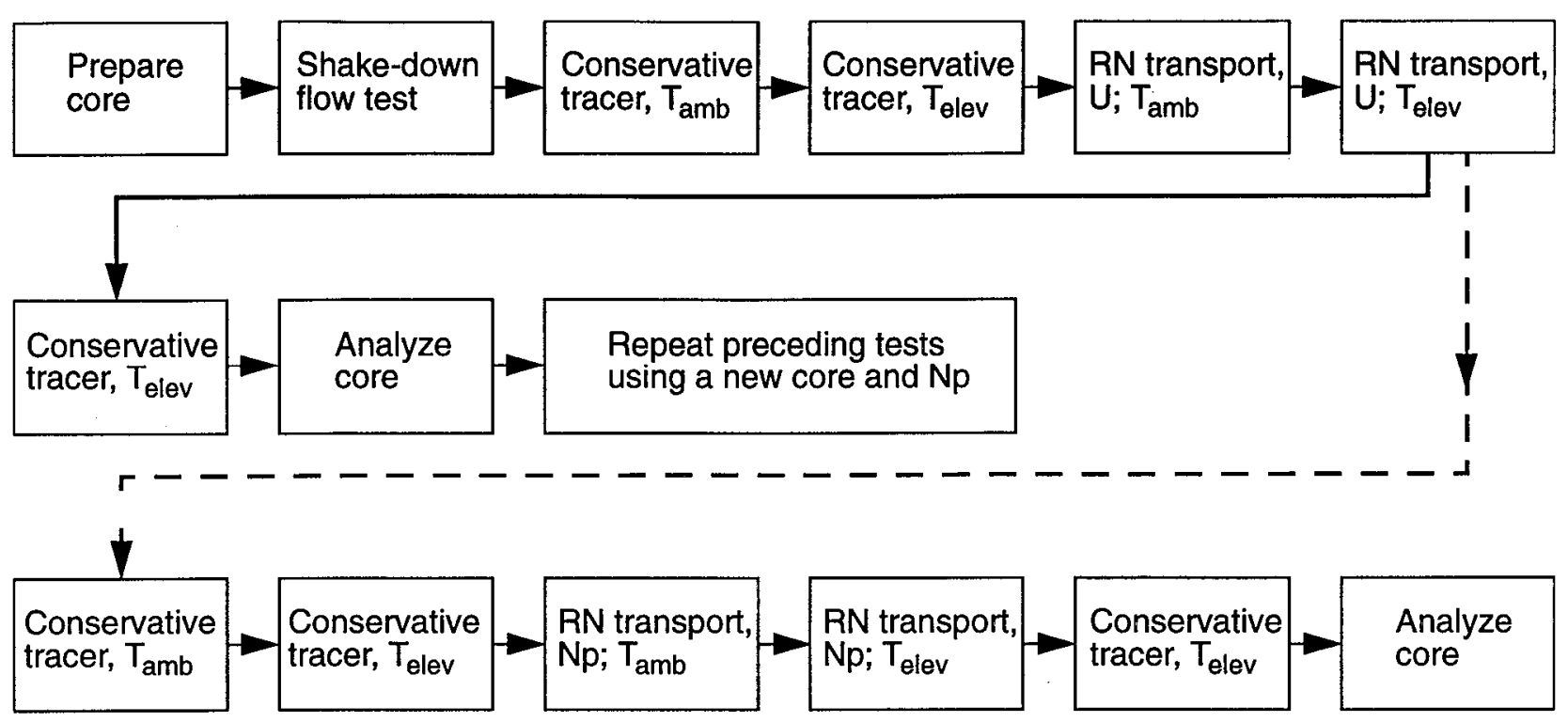

Figure 7. Flow chart depicting tasks for measuring transport properties of saw-cut Topopah Spring tuff. Dashed line represents pathway if it is feasible to utilize a single core sample for measuring both $\mathrm{U}$ and $\mathrm{Np}$ transport.

Table 1. Components of transport tests using Topopah Spring tuff with a saw-cut fracture.

Test Description

Prepare corc $\quad$ Prepare core to correct dimension, make and clean saw-cut fracture, examine saw-cut surface using scanning electron microscopy (SEM), measure connected porosity by water imbibition, jacket core with Viton.

Shake-down flow Prepare carrier solution, load core into pressure vessel, pressure check, autoclave test core in-situ, perform short-term flow test to assure operation of all components, perform baseline analysis of effluent ${ }^{(1)}$.

Conservative tracer Inject carrier solution plus $\mathrm{Br}^{-}$tracer into sample input valve (Figure 1), analyze effluent for $\mathrm{Br}^{-(2)}$ and major cations and anions; continue test until bulk of $\mathrm{Br}^{-}$is recovered.

RN transport Inject carrier solution plus radionuclide into sample input valve. Analyze effluent for radionuclide ${ }^{(3)}$ and major cations and anions.

Analyze core Disassemble apparatus, remove and dry core, examine saw-cut surface by SEM and possibly by autoradiography and secondary ion mass spectrometry (SIMS).

1. In addition to analysis for conservative and radionuclide tracers, selected samples of effluent fluids will be analyzed for most major and some trace metals using inductively coupled plasma spectroscopy (ICP), and anions using ion-chromatography, and dissolved inorganic $\mathrm{CO}_{2}$ analysis. Selected samples will also analyzed for suspended colloids using the techniques described in Viani and Martin (1994).

2. Bromide will be analyzed primarily by ion-selective electrode. Ion-chromatography will be used in cases where sample volume is limited.

3. Uranium will be analyzed using a pulsed laser fluorescence technique or potentially by ICP-mass spectroscopy, and Np will be analyzed by a liquid scintillation method or possibly by gamma or alpha spectrometry. 
Core Flow Experiment Protocol - MOLO4

\section{References}

Viani, B.E. and Martin, S.I. 1994. Groundwater Colloid Characterization. YMP milestone letter report MOL03.

Viani, B.E., and Martin, S.I. 1993. Core-flow Through Apparatus: Letter Report Documenting Testing Phase. YMP milestone report M0L06. 


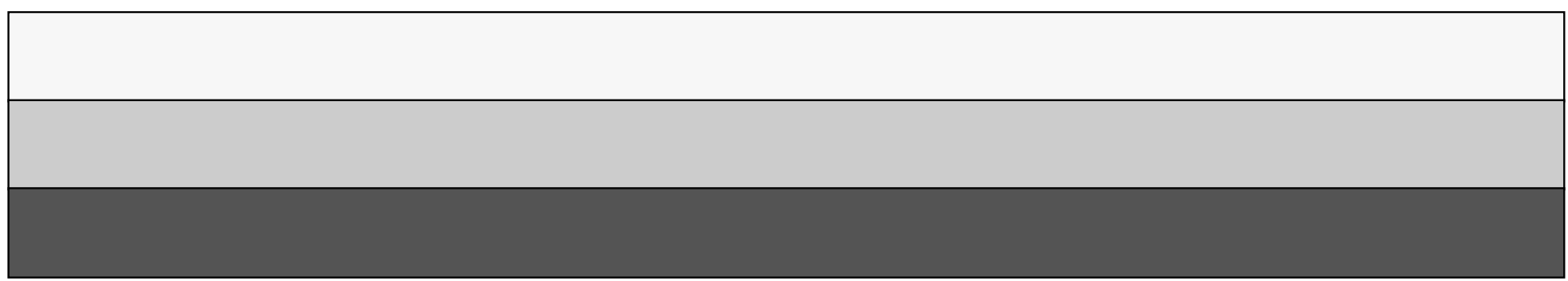

